\title{
Experience of malaria in children of a flood affected area: a field hospital study
}

M.F. Afzal' and M.A. Sultan ${ }^{7}$

$$
\text { معمد فهيم أفضل، محمد أشرف سلاريا سلطان المناطق المتضررة من الفيضان: دراسة لمستشفى ميداني }
$$

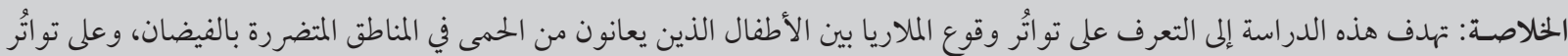

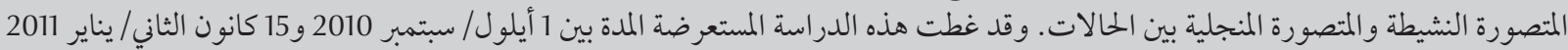

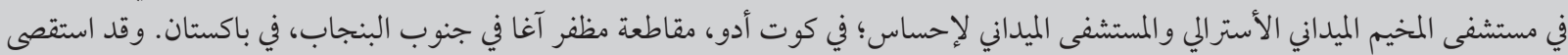

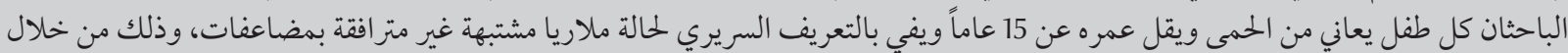

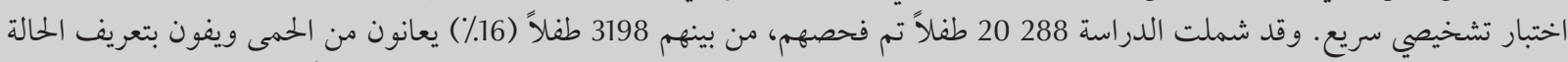

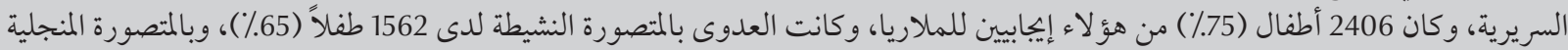

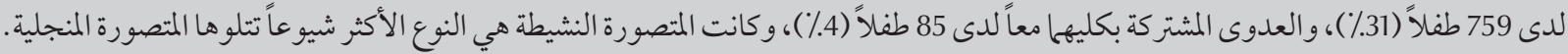

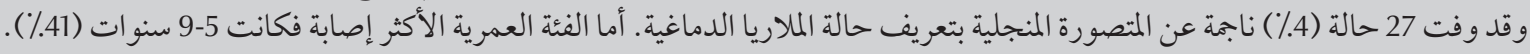

ABSTRACT To determine the frequency of malaria among children presenting with fever in a flood affected area, and the frequency of Plasmodium vivax and P. falciparum among cases, this cross-sectional study was conducted from 1 September 2010 to 15 January 2011 in the Australian Field Camp and Ehsas Field Hospital, Kot Addu, Muzaffargarh District, Southern Punjab, Pakistan. Each febrile child aged $\leq 15$ years fulfilling the clinical case definition of suspected uncomplicated malaria was investigated by rapid diagnostic test. Of 20288 children examined, 3198 (16\%) febrile patients fulfilled the clinical case definition and $2406(75 \%)$ cases were positive for malaria. P. vivax, P. falciparum, and co-infection were present in $1562(65 \%), 759(31 \%)$ and 85(4\%) cases respectively. $P$. vivax was the most prevalent species followed by $P$. falciparum. Twenty seven (4\%) cases of $P$. falciparum fulfilled the case definition of cerebral malaria. The age group most affected was 5-9 years (41\%).

Le paludisme chez des enfants vivant dans une zone touchée par des inondations : étude dans des hôpitaux de terrain

RÉSUMÉ Afin de déterminer la fréquence du paludisme chez des enfants souffrant de fièvre dans une zone touchée par des inondations et la fréquence de Plasmodium vivax et P. falciparum parmi les cas, la présente étude transversale a été menée entre le ${ }^{{ }^{\text {er }}}$ septembre 2010 et le 15 janvier 2011 à l'Australian Field Camp et l'Ehas Field Hospital, à Kot Addu, dans le district de Muzaffargarh, dans le sud du Pendjab (Pakistan). Chaque enfant fébrile âgé de 15 ans ou moins correspondant à la définition de cas clinique suspect de paludisme simple a subi un test diagnostique rapide. Sur les 20288 enfants examinés, 3198 patients fébriles $(16 \%)$ correspondaient à la définition de cas clinique et 2406 cas (75\%) étaient positifs pour le paludisme. $P$. vivax a été retrouvé chez 1562 enfants (65\%), P. falciparum chez 759 enfants (31\%) et une co-infection chez 85 cas (4\%). P. vivax était l'espèce la plus prévalente suivie par $P$. falciparum. Vingt-sept cas d'infection par $P$. falciparum $(4 \%)$ correspondaient à la définition de neuropaludisme. Les enfants âgés de cinq à neuf ans constituaient la tranche d'âge la plus touchée $(41 \%)$. 


\section{Introduction}

The World Health Organization (WHO) reported about 3.3 billion people at risk of malaria globally; this leads to about 250 million malaria cases and nearly 2 million deaths every year. The estimated number of annual malaria episodes in Pakistan is 1.5 million [1].

Malaria transmission risk can increase in natural disasters such as floods. During flooding, changes in human behavior and in the habitat can promote mosquito breeding. (e.g. river damming, and rerouting) [2].

The monsoon flood 2010 in Pakistan was the biggest disaster in history of the country. The National Disaster Management Authority estimated that over 17.6 million people were affected, exceeding the combined total of individuals affected by the 2004 Indian Ocean tsunami, the 2005 earthquake in northern areas of Pakistan and Kashmir and the 2010 Haiti earthquake [3]. The United Nations reported nearly 300000 suspected malaria cases in flood-affected areas from the end of July 2010 to October 2010 [4].

This study was conducted in 2 outreach field hospitals in Kot Addu to determine the frequency of malaria among children presenting with fever in the flood-affected area, and the frequency of Plasmodium vivax and P. falciparum among the malaria cases. Determining the species of Plasmodium in a community settings suffering from a disaster, where microscopy is not possible, is crucial. Healthcare personnel would thus be guided by the results of the malaria rapid diagnostic testing to decide on the most suitable course of treatment: chloroquine or artemisinin-based coms bination therapy.

\section{Methods}

This cross-sectional study was conducted from 1 September 2010 to 15 January 2011 in the Australian Field
Camp and Ehsas Field Hospital, Kot Addu, Muzaffargarh District, Southern Punjab, Pakistan. Kot Addu is a remote area along the river Indus in Southern Punjab, Pakistan which was among the regions most affected by flooding. The Australian Government established a medical relief camp in Kot Addu in September 2010. Later on, the 100-bed mobile Ehsas Field Hospital was established at the end of September 2010 in partnership with the Government of the Punjab and King Edward Medical University/Mayo Hospital, Lahore. The paediatric department of this field hospital was under the Department of Paediatrics, King Edward Medical University/Mayo Hospital, Lahore.

All children aged $\leq 15$ years who presented with a febrile illness were included in the study. A trained paediatric resident was deputed for patient evaluation. A total of 20288 children aged $\leq 15$ years were examined in the paediatric outpatient departments of both hospitals. Each febrile child was evaluated according to the clinical case definition of suspected malaria (history of recent fever, with $\geq 1$ among chills, headaches, body aches, perspiration, tiredness, and pallor) [5]. Thereafter, each child was investigated for evidence of malaria infection by CareStart malaria $\mathrm{pLDH} / \mathrm{HRP} 2$ combo rapid diagnostic test (RDT). The CareStart malaria pLDH/HRP2 combo RDT kits were provided by the WHO to detect $P$. falciparum and non-falciparum infections (or both) in community setting, distant from microscopy facilities [6].
These RDTs had a sensitivity of $96 \%$ and a specificity of $97 \%$ (manufacturer's data) [7]. Supervisors from the local Centre for Disease Control (CDC) and laboratory technicians from the field hospital were trained in the use of the CareStart malaria pLDH/HRP2 combo RDT and the interpretation of the results. Results were read after 20 minutes. A patient was labelled as a confirmed malaria case if they tested positive for one or both Plasmodium spp. [5]. Cases of cerebral malaria were also identified in line with the clinical case definition (fever, confusion, seizures, coma, and/or focal neurological signs) [5]. The information was recorded on a structured questionnaire.

Data were entered in SPSS, version 17. Each patient was treated on an individual basis. Cases of uncomplicated $P$. vivax malaria were treated with chloroquine and primaquine, while $P$. falciparum cases were treated with artemisinin-based therapy (Artesunate). Cases of cerebral malaria were referred to nearby tertiary care hospitals after initial emergency management.

\section{Results}

Out of 20288 children aged $\leq 15$ years presenting with fever, 3198 (16\%) fulfilled the clinical case definition of suspected uncomplicated malaria; 2406 (75\%) of these tested positive for malaria (confirmed cases). P. vivax was present in $1562(65 \%)$ cases, P.falciparum in $759(31 \%)$ and co-infection in 85 (4\%) (Table 1). Twenty seven (4\%)

\begin{tabular}{lcc}
\hline \multicolumn{2}{l}{ Table 1 Distribution of malaria cases and Plasmodium species $(\boldsymbol{n}=\mathbf{2 4 0 6})$} \\
\hline Cases & No. & $\%$ \\
Total examined & 20288 & 100 \\
Clinically suspected malaria & 3198 & 16 \\
Confirmed malaria & 2406 & 12 \\
P. vivax & 1562 & $65^{\mathrm{a}}$ \\
P. falciparum & 759 & $31^{\mathrm{a}}$ \\
Co-infection & 85 & $4^{\mathrm{a}}$ \\
\hline
\end{tabular}

${ }^{a}$ As percentage of confirmed cases. 
cases of P. falciparum malaria fulfilled the clinical case definition of cerebral malaria.

The most common age group affected was 5-9 years (41\%), followed by $10-15$ years ( $31 \%), 1-4$ years $(19 \%)$ and $<1$ year $(9 \%)$ (Figure 1).

\section{Discussion}

Our study shows that in children who presented with fever in the flood-affected region of Pakistan in 2010/2011, the incidence of suspected malaria was $16 \%$. The disease early warning system (DEWS) of the WHO estimated that out of 13095799 total consultations reported throughout the country from 29 July 2010 to 13 January 2011, 752637 (6\%) were for suspected malaria [8]. Similarly, in Punjab over the same period, of 2972893 total consultations (all age groups), suspected malaria was reported in $151785(5 \%)$ cases [8]. The difference may be due to the fact that our study focused on Southern Punjab while the WHO data was for whole province.

Our findings in regard to Plasmodium infection in febrile children in a flood-affected area are in accordance with those from $\mathrm{WHO}$, which reported both $P$. vivax and P. falciparum cases in Muzaffarghar district in Southern

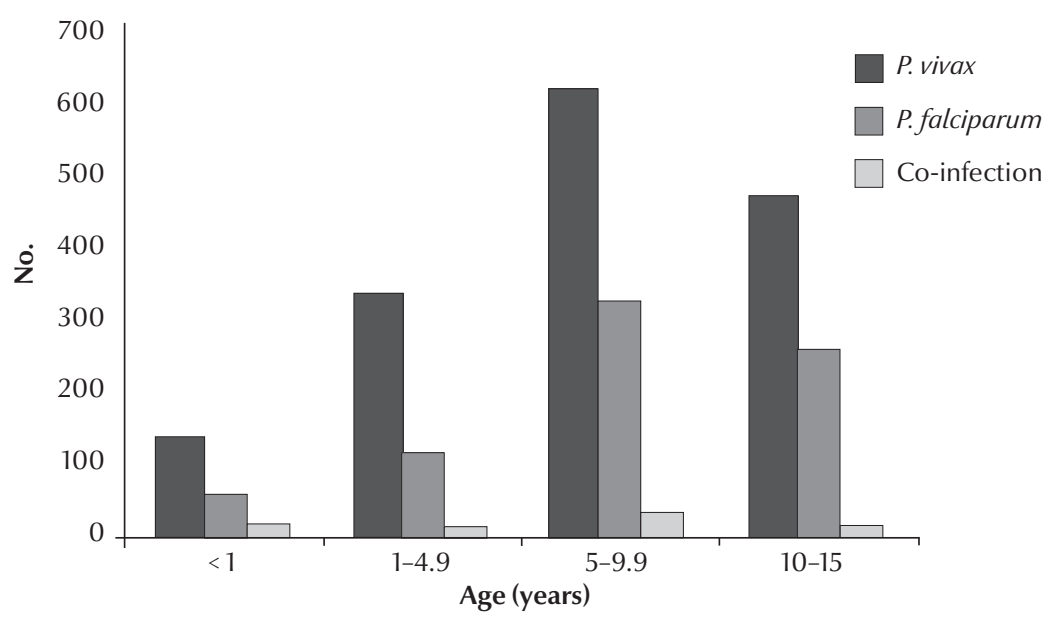

Figure 1 Age distribution of children $(n=2406)$ with clinically confirmed malaria in a flooded area in southern Punjab, 2010-2011
Punjab [8]. Looking at the international data from other flood-affected regions, we find epidemics of malaria in Costa Rica's Atlantic region in 1991, the Dominican Republic in 2004 [2], Surat, India in 2006 [9] and in eastern Yemen in 2008 [10].

Malaria case management remains a vital component of the malaria control strategies. This entails early diagnosis and prompt treatment with effective antimalarial medicines. In the present study, cases of uncomplicated P. vivax malaria were treated with chloroquine and primaquine, while P. falciparum cases were treated with artemisininbased therapy provided by WHO for disaster areas [6]. WHO recommends chloroquine combined with primaquine for uncomplicated $P$. vivax as treatment of choice for chloroquine-sensitive infection and artemisinin-based combination therapy (ACT) for treatment of uncomplicated $P$. falciparum malaria [11]. The National Malaria Control Programme in Pakistan has similar recommendations for the treatment of malaria infection [12]. However, WHO has also recommended that where ACT therapy has been adopted as the first line treatment for P. falciparum malaria, it may also be used for $P$. vivax malaria in combination with primaquine for radical cure [11]. A regional study reported

only $1.3 \%$ resistance to chloroquine for $P$. vivax and $P$. falciparum co-infection in 2006 [13] whereas the National Malaria Control Programme reported in 2007 that $40 \%$ of cases of P. falciparum were resistant to chloroquine [12].

In our population, even in disaster circumstances, $P$. vivax was more common (65\%). The National Malaria Control Programme also reported $P$. vivax as the dominant species (75\%) [12]. Similarly, studies in stable populations in Pakistan have shown a predominance of $P$. vivax in children $[13,14]$. Therefore, to guide the treatment of malaria, the correct approach would be to request confirmatory diagnosis of malaria in all suspected cases using microscopy, but in community settings like disaster areas, where microscopy is not possible, combination RDTs with high diagnostic performance for P. falciparum and P. vivax should be used to identify the species. Treatment with chloroquine or ACTs should then be guided by the results.

The strength of the present study is in being the first field hospital study from a disaster area to report on malaria infection along with Plasmodium spp. from one of the regions most affected by the floods in southern Punjab. The main limitation of our study was the lack of clinical follow-up of cases owing to the mass displacement and loss of communication in the disaster situation.

\section{Recommendations}

Suspicion for malaria among febrile children must be kept in mind in disaster circumstances. In the fields of community setting, distant from microscopy, it is recommended that combination RDTs with high diagnostic performance to $P$. falciparum and $P$. vivax should be used for the diagnosis. Treatment with either chloroquine or ACTs should be guided by the results. Early referral of non-responders is also recommended. We believe that malaria 
prevention awareness campaigns be launched in malaria-endemic and disaster-prone areas of the region.

\section{Acknowledgements}

The authors wish to thank Dr Ian Norton, Director, Disaster Preparedness and Response at the National Critical Care and Trauma Response Centre,Royal Darwin Hospital, Casurarina, Australia, Head of the Australian medical response team, for giving us the opportunity to work in the Australian field camp, Kot Addu. We are thankful to Mr Nadeem Chishti
(CDC supervisor, Ehsas Field Hospital, KotAddu) for his technical support. We are also grateful to the paediatric team who enthusiastically worked in Ehsas field hospital to serve the needy patients.

\section{Funding: None.}

Competing interests: None declared.

\section{References}

1. Malaria. Geneva, World Health Organization, 2011 (http:// www.who.int/topics/malaria/en/, accessed 11 May 2013).

2. Flooding and communicable diseases fact sheet. Geneva, World Health Organization, 2011 (http://www.who.int/hac/techguidance/ems/flood_cds/en/, accessed 11 May 2013).

3. Pakistan flood event recap report. London, AON Benfield, Impact Forecasting, 2010 (http://www.aon.com/attachments/reinsurance/201008_pakistan_flood.pdf, accessed 12 May 2013).

4. UN responds to malaria outbreak in flood-affected Pakistani provinces. New York, United Nations, UN News Centre, 2010 (http://www.un.org/apps/news/story.asp?NewsID=36411, accessed 12 May 2013).

5. Malaria (Plasmodium spp.) case definition. Atlanta, Centres for Disease Control, National Notifiable Diseases Surveillance System, 2010 (http://wwwn.cdc.gov/NNDSS/script/casedef. aspx?CondYrlD=759\&DatePub=1/1/2010 12:00:00 AM, accessed 13 May 2013).

6. WHO supports malaria epidemic prevention and control in Pakistan. Geneva, World Health Organization, Humanitarian Health Action, 2010 (http://www.who.int/hac/crises/pak/ releases/12october2010/en/index.html, accessed 13 May 2013).

7. Iqbal Jet al. Diagnosis of imported malaria by Plasmodium lactate dehydrogenase $(\mathrm{pLDH})$ and histidine-rich protein 2 (PfHRP-2)-based immunocapture assays. American Journal of Tropical Medicine and Hygiene, 2001, 64:20-23.

8. Weekly epidemiological bulletin. Flood response in Pakistan. Geneva, World Health Organization, Ministry of Health,
Government of Pakistan, 2011, 1(2):2 (http://www.who.int/ hac/crises/pak/sitreps/pakistan_epi_17january2011.pdf, accessed22 May 2013 )

9. Pawar AB et al. A rapid assessment of mosquito breeding, vector control measures and treatment seeking behaviour in selected slums of Surat, Gujarat, India, during post-flood period. Journal of Vector Borne Diseases, 2008, 45:325-327.

10. WHO rushes medical aid to flood hit areas of Yemen. Geneva, World Health Organization, Media Centre, 2008 (http:// www.who.int/mediacentre/news/releases/2008/pr39/en/ index.html, accessed 13 May 2013).

11. Guidelines for the treatment of malaria, 2nd ed. Geneva, World Health Organization, 2010:1-210 (http://whqlibdoc.who.int/ publications/2010/9789241547925_eng.pdf, accessed 13 May 2013).

12. Malaria case management: desk guide for clinicians and health care providers. Islamabad, Pakistan, Directorate of Malaria Control, Ministry of Health, 2007:1-40. (http://www.dmc. gov.pk/documents/pdfs/Case_Management_Guidelines. pdf, accessed 13 May 2013).

13. Jalal-Ud-Din, Khan SA, Ally SH. Malaria in children: study of 160 cases at a private clinic in Mansehra. Journal of Ayub Medical College, Abbottabad, 2006, 18:44-45.

14. Idris M, Sarwar J, Fareed J. Pattern of malarial infection diagnosed at Ayub Teaching Hospital Abbottabad. Journal of Ayub Medical College, Abbottabad, 2007, 19:35-36. 